\title{
The Crown with A Screw
}

\author{
Cristina-Stanca Molnar-Varlam, Csaba Joanovics, András Daradics, Attila Titus Augustus Szolon
}

University of Medicine and Pharmacy, Tîrgu Mureș, Romania

\section{CORRESPONDENCE}

Attila Titus Augustus Szolon Str. Gheorghe Marinescu nr. 38 540139 Tîrgu Mureș, Romania

Tel +40 746378726

E-mail:dr.szolontitus@yahoo.com

\section{ARTICLE HISTORY}

Received: March 2, 2017

Accepted: March 6, 2017
Cristina-Stanca Molnar-Varlam • Str. Gheorghe Marinescu nr. 38, 540139 Tîrgu Mureș, Romania, Tel: +40265215551

Csaba Joanovics - Str. Gheorghe Marinescu nr. 38 , 540139 Tîrgu Mureș, Romania, Tel: +40 265215551

András Daradics • Str. Gheorghe Marinescu nr. 38 , 540139 Tîrgu Mureș, Romania, Tel: +40 265215551
During certain dental treatments, there comes a point when the dentist, in order to counteract certain side effects, has to make a temporary prosthesis. An example would be the temporary prosthesis that is used during a long lasting endodontic treatment, when because of the advanced coronal destruction the occlusal stops are being lost. If this happens, the permanent prosthesis that follows is being compromised due to the extrusion of antagonist tooth.1-3

For this purpose, our team imagined a reliable, innovative and experimental solution to create a removable metal crown with a screw (Panel A). The crown has many advantages: it restores the dental morphology of the compromised tooth, maintaining the occlusal stops (Panel B); the crown cannot be removed by the patient, only the dentist can do it with a tiny screwdriver; if the patient is satisfied with the esthetics of the crown, it can be permanently bonded at the end of the treatment.

In order to manufacture the crown, we used metal alloy following a precise technique that required all of the dental technician's skills, but also those of the dentist who has to make a special preparation, similar to the on-lays (Panel C). It represents an exercise of mastery, the manufacturing of the thread being one of the most difficult steps of the process (Panel D). This is why we consider that the utility of the crown can also be didactic; dental technician students can practice their manual skills manufacturing it.

Unfortunately, not every tooth can receive such a crown. The most indicated teeth are the molars and rarely the premolars, because the margins of the preparation need to have a specific thickness $(2.5 \mathrm{~mm})$ in order to avoid a fracture (Panel E), as the crown has an original way of attaching to the tooth (Panel F).

In conclusion, this was a first enthusiastic attempt of making a temporary crown with a screw. Further in vitro and clinical studies have to be carried out in order to perfect this concept.

\section{REFERENCES}

1. Bratu D, Nussbaum R. Bazele clinice și tehnice ale protezării fixe. Bucharest: Editura medical, 2011; p. 491-495.

2. Rândașu I, Stanciu L. Restaurări protetice dentare fixe. Bucharest: Editura Meteor Press, 2006; p. 710715.

3. Molnar-Varlam CS, Székely MG, Mucenic GM. Materiale dentare. Tîrgu Mureș: Editura University Press, 2011; p. 49-51. 


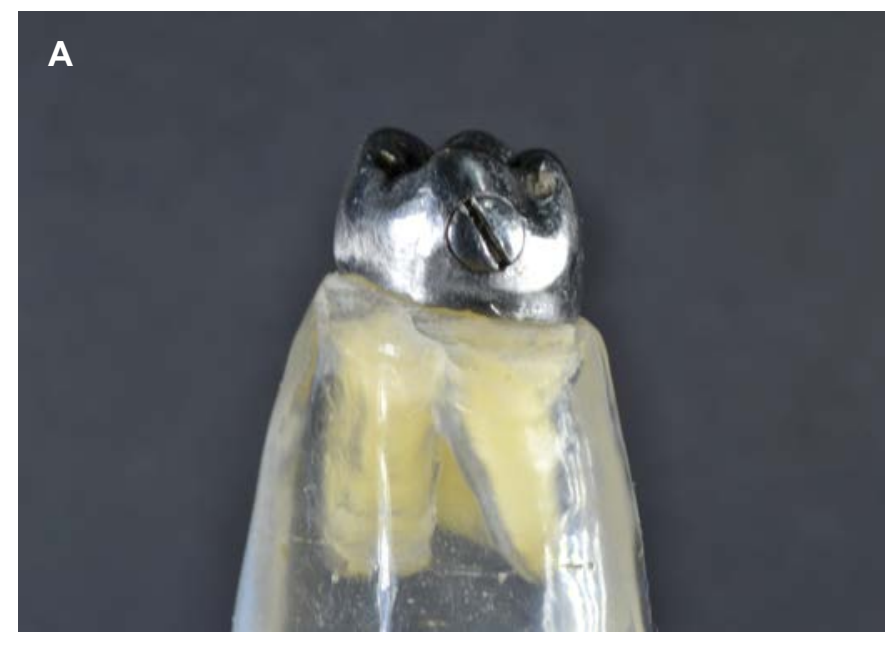

B
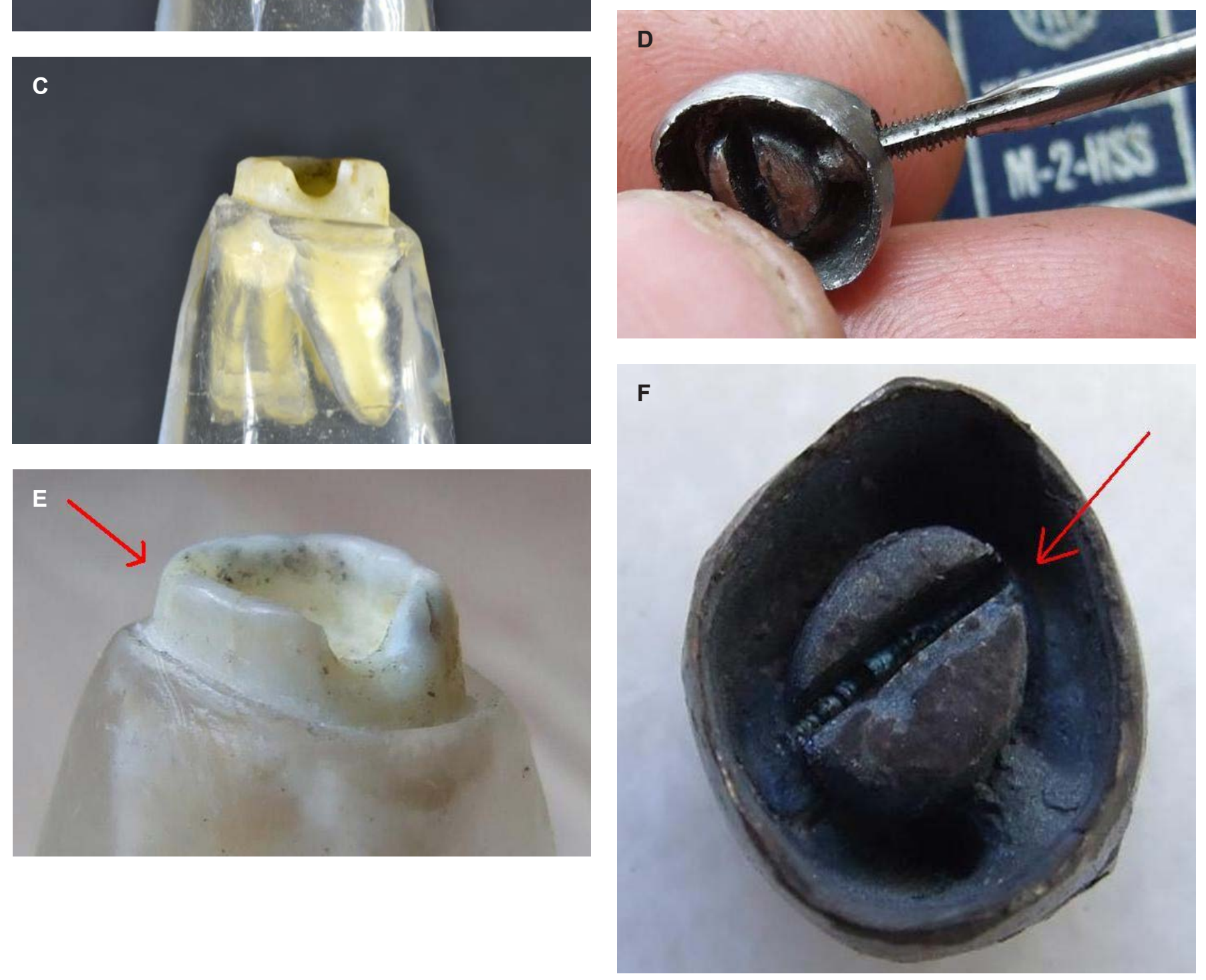